\title{
Neural mechanisms underlying the effects of face-based affective signals on memory for faces: a tentative model
}

\author{
Takashi Tsukiura* \\ Department of Cognitive and Behavioral Sciences, Graduate School of Human and Environmental Studies, Kyoto University, Kyoto, Japan
}

\section{Edited by:}

Florin Dolcos, University of Illinois at Urbana-Champaign, USA

\section{Reviewed by:}

Ullrich Wagner, Charité - University

Medicine Berlin, Germany

Ilona Croy, Technische Universitat,

Germany

Ilana Dew, Duke University, USA

\section{*Correspondence:}

Takashi Tsukiura, Department of Cognitive and Behavioral Sciences, Graduate School of Human and Environmental Studies, Kyoto University, Yoshida-Nihonmatsu-Cho, Sakyo-ku, Kyoto 606-8501, Japan. e-mail: tsukiura.takashi.6c@ kyoto-u.ac.jp
In our daily lives, we form some impressions of other people. Although those impressions are affected by many factors, face-based affective signals such as facial expression, facial attractiveness, or trustworthiness are important. Previous psychological studies have demonstrated the impact of facial impressions on remembering other people, but little is known about the neural mechanisms underlying this psychological process. The purpose of this article is to review recent functional MRI (fMRI) studies to investigate the effects of face-based affective signals including facial expression, facial attractiveness, and trustworthiness on memory for faces, and to propose a tentative concept for understanding this affective-cognitive interaction. On the basis of the aforementioned research, three brain regions are potentially involved in the processing of face-based affective signals. The first candidate is the amygdala, where activity is generally modulated by both affectively positive and negative signals from faces. Activity in the orbitofrontal cortex (OFC), as the second candidate, increases as a function of perceived positive signals from faces; whereas activity in the insular cortex, as the third candidate, reflects a function of face-based negative signals. In addition, neuroscientific studies have reported that the three regions are functionally connected to the memory-related hippocampal regions. These findings suggest that the effects of face-based affective signals on memory for faces could be modulated by interactions between the regions associated with the processing of face-based affective signals and the hippocampus as a memory-related region.

Keywords: fMRI, face, memory, amygdala, orbitofrontal cortex, insula

\section{INTRODUCTION}

Facial stimuli convey various types of information in human society, and are very important in non-verbal communication with others. For example, when we encounter someone for the first time, we try to read their feelings from their face. The facial information that can provide us with impressions of people includes many factors such as trustworthy, caring, responsible, emotionally stable, sociable, attractive, intelligent, confident, dominant, happy, aggressive threatening, mean, or weird features (Oosterhof and Todorov, 2008; Todorov and Engell, 2008; Todorov et al., 2008b), and it is also influenced by racial information (Stanley et al., 2011, 2012). Among them, three possible factors of facial expression, attractiveness, or trustworthiness are particularly important in forming the impressions of people and in selecting which people should be remembered, because the response times for the attractiveness and trustworthiness judgments were almost identical and faster than the response times for judgments of competence, likeability, and aggressiveness (Willis and Todorov, 2006). However, there is little evidence of the neural mechanisms underlying this psychological process. The aims of this article are to review psychological and cognitive neuroscience studies related to the effects of face-based affective signals on memory for faces, particularly those concerning facial expressions, attractiveness, and trustworthiness, and to propose a tentative framework for understanding the neural mechanisms of memory for faces in the context of human social interaction.

\section{EFFECTS OF FACE-BASED AFFECTIVE SIGNALS ON MEMORY FOR FACES: PSYCHOLOGICAL STUDIES}

The first main factor of face-based affective signals is facial expression. Previous psychological studies have reported that positive facial expressions such as smiling have a beneficial effect on remembering faces (D'Argembeau et al., 2003; D'Argembeau and van der Linden, 2004, 2007; Laroi et al., 2006; Shimamura et al., 2006; Ebner and Johnson, 2009). For example, Shimamura and his colleagues found that faces encoded with smiling expressions were remembered more accurately than those with other expressions, including surprise, anger, or fear (Shimamura et al., 2006). However, there is also evidence from psychological studies that positive facial expressions have no selective advantage on memory for faces. One study showed better remembering of faces with fearful expressions than of those with happy expressions (Righi et al., 2012), whereas another study reported memory enhancement for faces with positive and negative expressions, compared to those with neutral expressions (Foa et al., 2000). Taken together, both positive and negative facial expressions could contribute to the enhancing effects on memory for faces. 
The second main factor of affective signals conveyed from faces is facial attractiveness. The beneficial power of facial attractiveness has been observed in several studies investigating the recognition of other people. For example, adults (Langlois et al., 2000) as well as infants (Langlois et al., 1987) show a preference for attractive faces. Also, compared to facially unattractive people, facially attractive people are likely to show enhanced positive behavior in a social way (Langlois et al., 2000), and to be judged people with better personality by others (Dion et al., 1972). The positive bias toward attractive faces has been identified in memory for faces, in which attractive faces are better remembered than unattractive faces (Cross et al., 1971; Marzi and Viggiano, 2010). However, there is evidence from psychological studies that the distinctiveness in attractive faces is low, and the low distinctiveness of faces has little beneficial effect on memory for faces (Light et al., 1981). Thus, the effect of facial attractiveness on memory for faces may be advantageous, but the mechanisms underlying it and its efficiency in terms of remembering faces are still controversial.

The third main factor of face-based affective signals enhancing the memory processing of faces is facial trustworthiness. There is evidence from psychological studies that facial untrustworthiness has a beneficial power on memory for faces. For example, one psychological study demonstrated that the recognition of faces with untrustworthy impressions was better than that of faces with neutral or trustworthy impressions (Mealey et al., 1996). Another psychological study found that the faces of trustworthylooking people with bad personality traits were remembered more accurately than those of untrustworthy-looking people with bad personality traits (Suzuki and Suga, 2010). In this study, 58 college students played a debt game, where they learned to discriminate among good, neutral, and bad lenders, who respectively charged no, moderate, and high interest on the debt. Each lender had either a trustworthy- or untrustworthy-looking faces. The findings of better memory for people associated with an untrustworthy impression or bad personality, which depends on the face-based first impression or on the later contextual information of personality, suggest that humans could be equipped with protective mechanisms against people with really bad personality traits (Suzuki and Suga, 2010).

\section{ROLES OF THE AMYGDALA IN THE PROCESSING OF FACE-BASED AFFECTIVE SIGNALS}

The first candidate region associated with the processing of face-based affective signals is the amygdala (Figure 1). Previous functional neuroimaging studies have reported that the amygdala shows significant activations during the processing of face-based negative and positive signals including happy, sad, and fearful expressions (Fusar-Poli et al., 2009). For example, activity of the amygdala was greater during perceiving high-intensity expressions than low-intensity expressions, and the activity was identified in relation to both positive and negative signals from faces (Winston et al., 2003). This suggests that activity of the amygdala could be modulated by affective intensities of facial expressions. However, there is functional neuroimaging evidence linking amygdala activities to the processing of negative facial expressions (Vuilleumier and Pourtois, 2007). For example, one functional MRI (fMRI) study demonstrated that the amygdala showed greater activity during the processing of negative facial expressions than of neutral facial expressions (Iidaka et al., 2001). Amygdala responses selective to negative facial expressions have been observed in other functional neuroimaging and lesion studies (Adolphs et al., 1994; Morris et al., 1996; Broks et al., 1998). The amygdala, in which the activity is modulated by affective intensities of facial expressions, could be involved in the processing of both positive and negative facial expressions, but the involvement could be biased toward more negative expressions. However, given that a meta-analysis study showed no effect of angry and disgusted expressions on amygdala activations (FusarPoli et al., 2009), further investigations would be required to clarify whether the amygdala activations are modulated only by specific types of facial expressions, rather than affective intensities of facial expressions.

The contribution of the amygdala to the processing of facial attractiveness or trustworthiness has also been demonstrated in cognitive neuroscience studies (Bzdok et al., 2011). Several functional neuroimaging studies have reported greater amygdala activity in the processing of highly attractive and unattractive faces than of middle-ranked attractive faces (Winston et al., 2007; Cloutier et al., 2008; Liang et al., 2010). Additionally, there is functional neuroimaging evidence that amygdala activity increased during the processing of both trustworthy and untrustworthy faces, compared to that of neutral faces (Todorov, 2008). For example, one fMRI study found that the amygdala showed greater responses to highly trustworthy as well as to highly untrustworthy faces than to neutral faces (Said et al., 2009). The non-linear amygdala responses to face-based affective signals suggest that this region could be involved in sensing the value of social stimuli including both positive and negative affects of faces. However, other functional neuroimaging studies have demonstrated that the amygdala response to faces increased as their perceived untrustworthiness increased (Winston et al., 2002; Engell et al., 2007; Todorov et al., 2008a), and this amygdala response to untrustworthy faces was supported by a lesion study (Adolphs et al., 1998). Taken together, amygdala responses to facial attractiveness and trustworthiness could be possibly modulated by both good and bad impressions of the two factors, but the responses could be biased to more negative signals conveyed from faces. However, further studies would be required to clarify whether the amygdala activity is modulated by facial impressions or by affective intensities of presented pictures.

\section{ROLES OF THE ORBITOFRONTAL CORTEX IN THE PROCESSING OF FACE-BASED AFFECTIVE SIGNALS}

The second candidate region associated with the processing of face-based affective signals is the medial orbitofrontal cortex (OFC: Figure 2). The involvement of the medial OFC region in the processing of facial expressions has been identified when the facial expression is happy or smiling. For example, activity of the medial OFC region was enhanced in the processing of happy facial expressions, compared to that of facial expressions of disgust (Gorno-Tempini et al., 2001). The medial OFC responses to happy facial expressions have also been found in other functional neuroimaging studies (O’Doherty et al., 2003; Minagawa-Kawai 

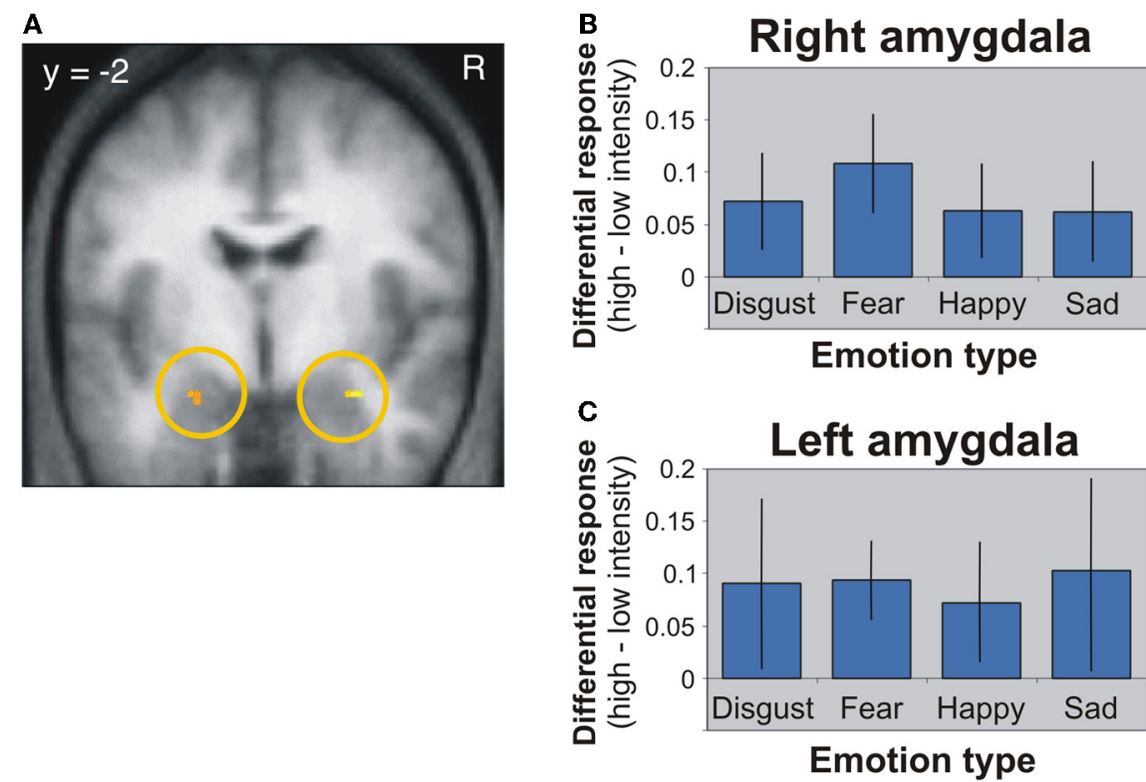

FIGURE 1 | Amygdala activation in response to different facial expressions (Winston et al., 2003). (A) Activation image of the amygdala during the processing of high-intensity expressions compared to low-intensity expressions. (B) Activation profiles of the right amygdala. (C) Activation profiles of the left amygdala. This figure was reused with the permission.

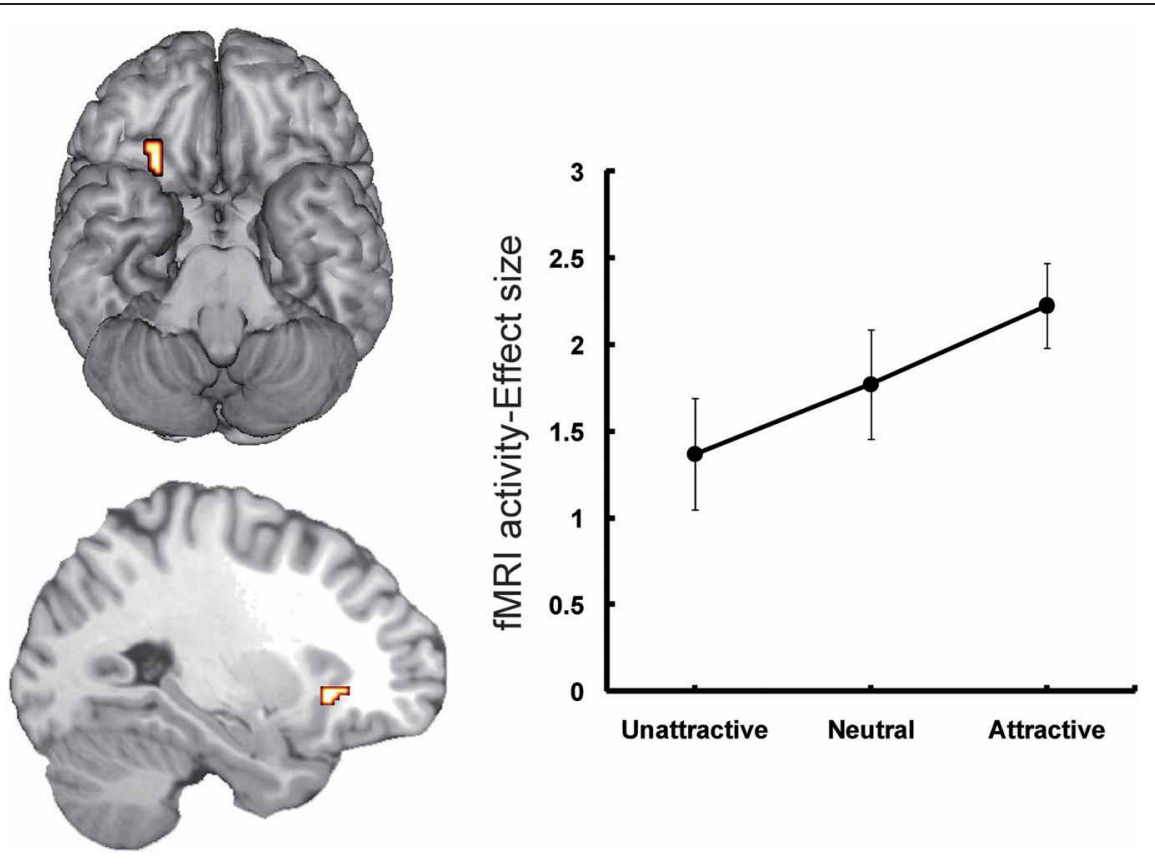

FIGURE 2 | Orbitofrontal activations in response to attractive faces (Tsukiura and Cabeza, 2011a). Activity of the OFC reflected an increasing function of facial attractiveness. This figure was reused with the permission.

et al., 2009). However, given that a meta-analysis study failed to identify significant activations in the medial OFC region during the processing of happy facial expressions (Fusar-Poli et al., 2009), it is possible that a greater response of this region to happy facial expressions may be limited in some specific situations, such as the explicit processing of happy facial expressions (GornoTempini et al., 2001) or the social processing of smiling faces (Minagawa-Kawai et al., 2009).

Moreover, functional neuroimaging studies have linked the medial OFC regions to the processing of attractive faces as 
one of the positive affective signals from faces (Aharon et al., 2001; O'Doherty et al., 2003; Kranz and Ishai, 2006; Bray and O'Doherty, 2007; Ishai, 2007; Winston et al., 2007; Cloutier et al., 2008; Liang et al., 2010; Tsukiura and Cabeza, 2011a,b). The roles of this region in the processing of face-based positive signals have also been observed when the personality traits estimated from faces are trustworthy. For example, medial OFC activity reflected an increasing function of trustworthiness for self-resembling faces (Platek et al., 2009), and of personality traits estimated from sentences describing hypothetical actions (Tsukiura and Cabeza, 2011b). Taken together, activity of the medial OFC region could be modulated by facial attractiveness and positive attributes of personality estimated from faces.

The important role of the medial OFC in the processing of rewards has been demonstrated by cognitive neuroscience studies involving animal and human subjects (Rolls, 2000; Martin-Soelch et al., 2001; McClure et al., 2004; O’Doherty, 2004). For example, single unit recording studies with non-human primates have shown that the medial OFC contributes to the coding of reward values of stimuli (Rolls et al., 1989; Critchley and Rolls, 1996). Likewise, functional neuroimaging studies involving human subjects have reported that activity in the medial OFC region is associated with coding rewards from a variety of sensory modalities, including taste, olfaction, somatosensory, auditory, and vision, as well as more abstract rewards such as money (O'Doherty, 2004). In addition, one study found greater activity in this region when subjects viewed beautiful paintings than when they viewed ugly paintings, regardless of the category of painting (Kawabata and Zeki, 2004). Thus, the response bias toward affectively positive signals from faces could be strongly associated with rewardrelated activity in the medial OFC region. This implication is supported by functional neuroimaging evidence, in which attractive faces increased activations in the medial OFC as well as the nucleus accumbens comprising the putative reward circuit (Cloutier et al., 2008).

However, several studies have implied that roles in the OFC region may be dissociable between medial and lateral portions of this region. For example, one fMRI study reported that activity in the medial OFC region was positively correlated with an increasing function of facial attractiveness, whereas the lateral OFC region showed a reverse pattern of activity (O'Doherty et al., 2003). Another fMRI study, which investigated activations associated with the onset or offset of emotional expressions, demonstrated that the medial OFC region showed greater activity during the processing of positive expressions (offset of angry expression), and that activity in the lateral OFC region reflected both conditions of negative (onset of angry expression and offset of happy expression) and positive expressions (offset of angry expression) (Muhlberger et al., 2011). These findings suggest that roles of the lateral OFC in the processing of facebased affective signals may be different from those of the medial OFC, but the precise roles in the lateral OFC region are still controversial.

\section{ROLES OF THE INSULAR CORTEX IN THE PROCESSING OF FACE-BASED AFFECTIVE SIGNALS}

The third candidate region associated with the processing of face-based affective signals is the insular cortex (Figure 3). Cognitive neuroscience studies have reported that the insular cortex is involved in the processing of affectively negative facial expressions, in particular expressions of disgust (Phillips et al., 1997, 1998; Sprengelmeyer et al., 1998; Sambataro et al., 2006). Additionally, insular activations during the processing of negative facial expressions have been identified in association with expressions of pain (Botvinick et al., 2005), or with the offset of happy expressions and the onset of angry expressions (Muhlberger et al., 2011). There is also functional neuroimaging evidence that the insula shows greater activity during the processing of unattractive faces than during that of attractive faces (O'Doherty et al., 2003; Krendl et al., 2006; Tsukiura and Cabeza, 2011b), and during the processing of untrustworthy faces than of trustworthy faces (Winston et al., 2002; Krendl et al., 2006; Tsukiura et al., 2012). Thus, insular activities could be modulated by facebased negative signals, which include both external features, such

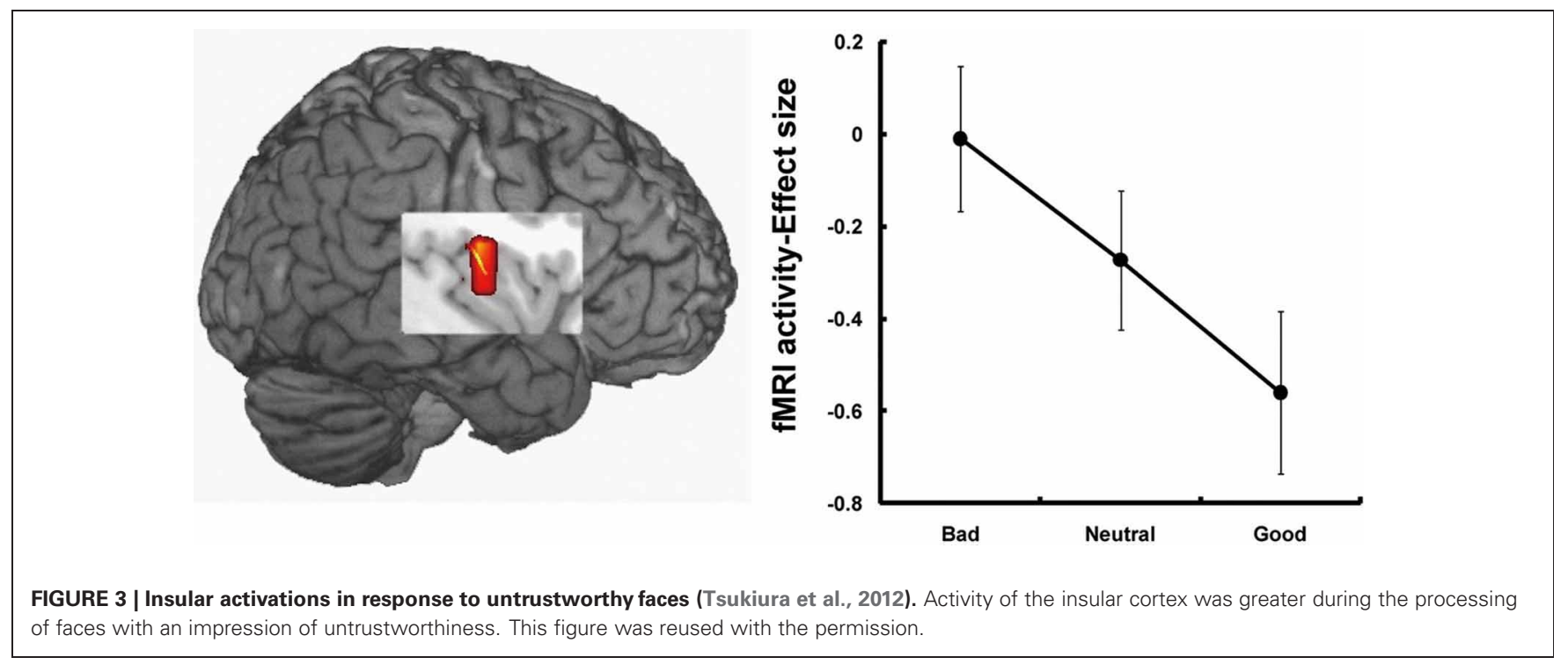


as negative facial expressions or unattractiveness of faces, and negative personality traits, such as untrustworthiness.

Functional neuroimaging studies have demonstrated that the insular cortex shows increasing activity associated with a variety of negative social situations, including social exclusion (Eisenberger et al., 2003), unfairness (Sanfey et al., 2003), and unreciprocated cooperation (Rilling et al., 2008). The insular activity has also been linked to the processing of pain (Critchley et al., 2000) and aversive conditioning (Seymour et al., 2004). These findings suggest that the insular cortex could contribute to an avoidance response away from people with face-based negative signals. The link between insular cortex and avoidance responses is consistent with findings that insular activity is involved in the anticipation of threat (Seymour et al., 2007), the avoidance of risky options in decision-making tests (Kuhnen and Knutson, 2005), and individual differences in avoidance learning (Samanez-Larkin et al., 2008).

\section{ROLES OF THE HIPPOCAMPUS AND FUSIFORM GYRUS IN MEMORY FOR FACES}

One of the important regions in memory for face-related information is the hippocampus. Functional neuroimaging studies have reported that the hippocampus as the medial temporal lobe (MTL) memory system is involved in the encoding and retrieval of episodic memory details including contextual information of an event (Davachi, 2006; Diana et al., 2007; Eichenbaum et al., 2007). The importance of this region have also been observed in the encoding and retrieval of face-related memories (Small et al., 2001; Sperling et al., 2001, 2003; Paller et al., 2003; Zeineh et al., 2003; Kirwan and Stark, 2004; Chua et al., 2007; Tsukiura et al., 2008, 2011). For example, one fMRI study showed hippocampal activations during the successful retrieval of both face-name associations and face-job title associations, and the hippocampal activations were significantly declined in older adults, compared to young adults (Tsukiura et al., 2011). In addition, hippocampal contributions to face-related memories have been identified in the processing of memory for face-scene associations (Hayes et al., 2010), or face-face and face-laugh associations (Holdstock et al., 2010). These findings suggest that the hippocampus could be involved in memory for details of face-related information.

Another important region in face memories is the right fusiform region, in which a region selective to the processing of face information is known as the fusiform face area (FFA; Kanwisher et al., 1997). Functional neuroimaging studies have reported that both FFA and hippocampal regions show significant activations during the successful encoding or retrieval of facial stimuli (Prince et al., 2009; Skinner et al., 2010). One theory of episodic memory consolidation proposes that components forming episodic memories are stored in unimodal or heteromodal association cortices, and that the hippocampus binds these components with event-specific contextual information (Alvarez and Squire, 1994; Mishkin et al., 1997; Nadel and Moscovitch, 1997; Fujii et al., 2000; Shastri, 2002; Norman and O'Reilly, 2003). Taken together, face memories could be successfully encoded or retrieved by the FFA-hippocampal network, in which facial stimuli processed in FFA are bound with the specific contextual information by the hippocampus.

\section{NEURAL MECHANISMS UNDERLYING THE EFFECTS OF FACE-BASED AFFECTIVE SIGNALS ON MEMORY FOR FACES}

The importance of the amygdala, medial OFC, and insula in the processing of face-based affective signals has been identified in cognitive neuroscience studies. These studies have demonstrated that the amygdala contributes to the processing of both positive and negative affective signals from faces, and that medial OFC activity shows biased responses to positively affective signals from faces, whereas insular activity is modulated by negatively affective signals from faces. In addition, recent advances in effective connectivity analysis in functional neuroimaging studies have shown that the effective connectivity between the amygdala and medial OFC contributes to the differentiation of positive and neutral facial expressions from negatively valenced angry, disgust, and fear expressions (Liang et al., 2009), and that the effective connectivity between the amygdala and insula is associated with the processing of facial expressions of disgust (Tettamanti et al., 2012). Another fMRI study revealed that activities in the medial OFC region, which is involved in the processing of facial attractiveness and personality goodness, were negatively correlated with activities in the insular cortex, which is involved in the processing of facial unattractiveness and personality badness (Tsukiura and Cabeza, 2011b). These findings suggest that the amygdala-medial OFC-insula network could contribute to forming impressions of people by face-based affective signals. The amygdala could act as a primary system of face-based affective signals by responding to their intensity, and could adjust interacting activities between the medial OFC, which is involved in the processing of positively valenced signals from faces, and insula, which is involved in the processing of negatively valenced signals from faces (Figure 4).

The modulatory effects of face-based affective signals on memory for faces could be mediated by an interaction between

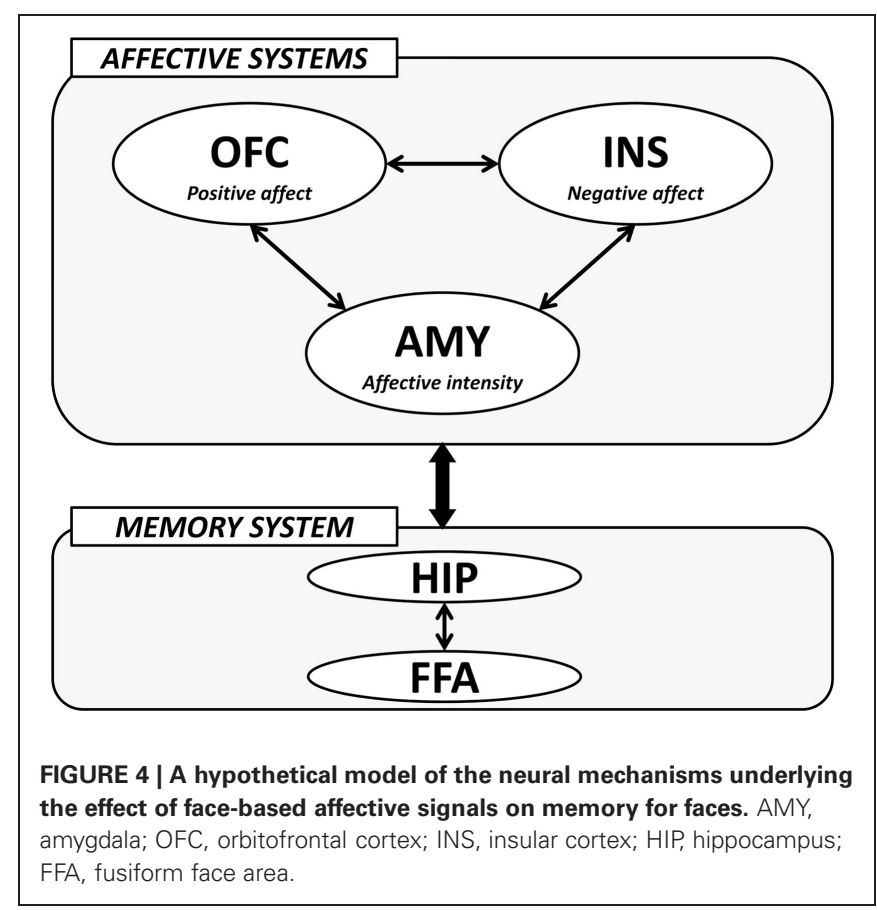


affective systems including the amygdala, medial OFC, and insula, and memory system including the hippocampus and FFA (Figure 4). For example, functional neuroimaging studies have reported that both hippocampal and FFA regions show significant activations during the encoding and retrieval of faces (Prince et al., 2009; Skinner et al., 2010), and that faces with emotional expressions are remembered more accurately than those with neutral expressions by an effect of the affect-related amygdala (Fenker et al., 2005) or medial OFC (Tsukiura and Cabeza, 2008) activities on the memory-related hippocampal activities. The effects of face-based affective signals on memory for faces have also been identified in the processing of attractive faces, better memory for which is modulated by an interaction between activities in the medial OFC and hippocampus (Tsukiura and Cabeza, 2011a). Moreover, an interaction between the insula, which is associated with the processing of untrustworthy impressions, and the hippocampus is important in the enhancement of memory for untrustworthy faces (Tsukiura et al., 2012). These findings suggest that the amygdala, medial OFC, and insula as affective systems could directly or indirectly interact with the hippocampus-FFA network as memory system, and that the functional connection could contribute to the enhancement of memory for faces by face-based affective signals. Given that the interactions between affect-related regions and memory-related regions were identified in encoding (Tsukiura and Cabeza, 2011a; Tsukiura et al., 2012), retrieval (Fenker et al., 2005), or both (Tsukiura and Cabeza, 2008), the functional connection could be shared between these processes.

However, the possible interaction between regions as affective systems and memory system in memory for (affective) faces has been identified in memory for other affective stimuli such as affective pictures (LaBar and Cabeza, 2006; Dolcos et al., 2012). Thus, the model presented here is preliminary or tentative, because evidence whether an interaction between affective- and

\section{REFERENCES}

Adolphs, R., Tranel, D., and Damasio, A. R. (1998). The human amygdala in social judgment. Nature 393, 470-474.

Adolphs, R., Tranel, D., Damasio, H., and Damasio, A. (1994). Impaired recognition of emotion in facial expressions following bilateral damage to the human amygdala. Nature 372, 669-672.

Aharon, I., Etcoff, N., Ariely, D., Chabris, C. F., O'Connor, E., and Breiter, H. C. (2001). Beautiful faces have variable reward value: fMRI and behavioral evidence. Neuron 32, 537-551.

Alvarez, P., and Squire, L. R. (1994). Memory consolidation and the medial temporal lobe: a simple network model. Proc. Natl. Acad. Sci. U.S.A. 91, 7041-7045.

Botvinick, M., Jha, A. P., Bylsma, L. M., Fabian, S. A., Solomon, P. E., and Prkachin, K. M. (2005). Viewing facial expressions of pain engages cortical areas involved in the direct experience of pain. Neuroimage 25, 312-319.

Bray, S., and O'Doherty, J. (2007). Neural coding of reward-prediction error signals during classical conditioning with attractive faces. $J$. Neurophysiol. 97, 3036-3045.

Broks, P., Young, A. W., Maratos, E. J., Coffey, P. J., Calder, A. J., Isaac, C. L., Mayes, A. R., Hodges, J. R., Montaldi, D., Cezayirli, E., Roberts, N., and Hadley, D. (1998). Face processing impairments after encephalitis: amygdala damage and recognition of fear. Neuropsychologia 36, 59-70.

Bzdok, D., Langner, R., Caspers, S., Kurth, F., Habel, U., Zilles, K., Laird, A., and Eickhoff, S. B. (2011). ALE meta-analysis on facial judgments of trustworthiness and attractiveness. Brain Struct. Funct. 215, 209-223.

memory-related regions in our model is applied only to the memory for faces or to the affective memory in general is still scarce. Additional supports by future studies would be needed to clarify the neural mechanisms involved in the modulatory effects of face-based affective signals on memory for faces, and which of these mechanisms are specific to facial stimuli.

\section{CONCLUSION}

This review article outlined the neural mechanisms underlying the effects of facial impressions on memory for faces by discussing previous functional neuroimaging findings. Information related to face-based affective signals consists of several factors such as facial expression, facial attractiveness, and trustworthiness, and is mediated by the amygdala, medial OFC, and insular regions as the affective system. Behaviorally, memory for faces is often enhanced by these kinds of face-based affective signals, and the memory enhancement is explained in terms of the modulatory effects of affect-related regions on the memory-related hippocampal region. In our daily lives, we have some impression of others on the basis of face-based affective signals, and the impression of others is important in deciding whether they should be approached or avoided. These effects of enhancement (approach) and impairment (avoidance) on perceiving people are influential in memory for faces. Face-based affective signals, as well as interpersonal relationship (Cacioppo and Cacioppo, 2012; Powers and Heatherton, 2012), could be important in remembering who should be approached or avoided in the context of social interaction.

\section{ACKNOWLEDGMENTS}

This work was supported by the Funding Program for Next Generation World-Leading Researchers (LZ001) from the Cabinet Office, Government of Japan.

Cacioppo, S., and Cacioppo, J. T. (2012). Decoding the invisible forces of social connections. Front. Integr. Neurosci. 6:51. doi: 10.3389/fnint.2012.00051

Chua, E. F., Schacter, D. L., RandGiovannetti, E., and Sperling, R. A. (2007). Evidence for a specific role of the anterior hippocampal region in successful associative encoding. Hippocampus 17, 1071-1080.

Cloutier, J., Heatherton, T. F., Whalen, P. J., and Kelley, W. M. (2008). Are attractive people rewarding? Sex differences in the neural substrates of facial attractiveness. J. Cogn. Neurosci. 20, 941-951.

Critchley, H. D., Elliott, R., Mathias, C. J., and Dolan, R. J. (2000) Neural activity relating to generation and representation of galvanic skin conductance responses: a functional magnetic resonance imaging study. J. Neurosci. 20, 3033-3040.
Critchley, H. D., and Rolls, E. T. (1996). Hunger and satiety modify the responses of olfactory and visual neurons in the primate orbitofrontal cortex. J. Neurophysiol. 75, 1673-1686.

Cross, J. F., Cross, J., and Daly, J. (1971). Sex, race, age and beauty as factors in recognition of faces. Percept. Psychophys. 10, 393-396.

D'Argembeau, A., and van der Linden, M. (2004). Identity but not expression memory for unfamiliar faces is affected by ageing. Memory 12, 644-654.

D'Argembeau, A., and van der Linden, M. (2007). Facial expressions of emotion influence memory for facial identity in an automatic way. Emotion 7, 507-515.

D'Argembeau, A., van der Linden, M., Comblain, C., and Etienne, A. M. (2003). The effects of happy and angry expressions on identity and expression memory for 
unfamiliar faces. Cogn. Emot. 17, 609-622.

Davachi, L. (2006). Item, context and relational episodic encoding in humans. Curr. Opin. Neurobiol. 16, 693-700.

Diana, R. A., Yonelinas, A. P., and Ranganath, C. (2007). Imaging recollection and familiarity in the medial temporal lobe: a threecomponent model. Trends Cogn. Sci. 11, 379-386.

Dion, K., Berscheid, E., and Walster, E. (1972). What is beautiful is good. J. Pers. Soc. Psychol. 24, 285-290.

Dolcos, F., Denkova, E., and Dolcos, S. (2012). Neural correlates of emotional memories: a review of evidence from brain imaging studies. Psychologia. (in press).

Ebner, N. C., and Johnson, M. K. (2009). Young and older emotional faces: are there age group differences in expression identification and memory? Emotion 9, 329-339.

Eichenbaum, H., Yonelinas, A. P., and Ranganath, C. (2007). The medial temporal lobe and recognition memory. Annu. Rev. Neurosci. 30, 123-152.

Eisenberger, N. I., Lieberman, M. D., and Williams, K. D. (2003). Does rejection hurt? An fMRI study of social exclusion. Science 302, 290-292.

Engell, A. D., Haxby, J. V., and Todorov, A. (2007). Implicit trustworthiness decisions: automatic coding of face properties in the human amygdala. J. Cogn. Neurosci. 19, 1508-1519.

Fenker, D. B., Schott, B. H., Richardson-Klavehn, A., Heinze, H. J., and Duzel, E. (2005). Recapitulating emotional context: activity of amygdala, hippocampus and fusiform cortex during recollection and familiarity. Eur. J. Neurosci. 21, 1993-1999.

Foa, E. B., Gilboa-Schechtman, E., Amir, N., and Freshman, M. (2000). Memory bias in generalized social phobia: remembering negative emotional expressions. J. Anxiety Disord. 14, 501-519.

Fujii, T., Moscovitch, M., and Nadal, L. (2000). "Memory consolidation, retrograde amnesia, and the temporal lobe," in Handbook of Neuropsychology, 2nd Edn. ed L. S. Cermak (Amsterdam: Elsevier), 223-250.

Fusar-Poli, P., Placentino, A., Carletti, F., Landi, P., Allen, P., Surguladze, S., Benedetti, F., Abbamonte, M., Gasparotti, R., Barale, F., Perez, J., McGuire, P., and Politi, P. (2009). Functional atlas of emotional faces processing: a voxel-based metaanalysis of 105 functional magnetic resonance imaging studies. $J$. Psychiatry Neurosci. 34, 418-432.

Gorno-Tempini, M. L., Pradelli, S., Serafini, M., Pagnoni, G., Baraldi, P., Porro, C., Nicoletti, R., Umita, C., and Nichelli, P. (2001). Explicit and incidental facial expression processing: an fMRI study. Neuroimage 14, 465-473.

Hayes, S. M., Baena, E., Truong, T. K., and Cabeza, R. (2010). Neural mechanisms of context effects on face recognition: automatic binding and context shift decrements. J. Cogn. Neurosci. 22, 2541-2554.

Holdstock, J. S., Crane, J., Bachorowski, J. A., and Milner, B. (2010). Equivalent activation of the hippocampus by face-face and face-laugh paired associate learning and recognition. Neuropsychologia 48, 3757-3771.

Iidaka, T., Omori, M., Murata, T., Kosaka, H., Yonekura, Y., Okada, T., and Sadato, N. (2001). Neural interaction of the amygdala with the prefrontal and temporal cortices in the processing of facial expressions as revealed by fMRI. J. Cogn. Neurosci. 13, 1035-1047.

Ishai, A. (2007). Sex, beauty and the orbitofrontal cortex. Int. J. Psychophysiol. 63, 181-185.

Kanwisher, N., McDermott, J., and Chun, M. M. (1997). The fusiform face area: a module in human extrastriate cortex specialized for face perception. J. Neurosci. 17, 4302-4311.

Kawabata, H., and Zeki, S. (2004). Neural correlates of beauty. J. Neurophysiol. 91, 1699-1705.

Kirwan, C. B., and Stark, C. E. L. (2004). Medial temporal lobe activation during encoding and retrieval of novel face-name pairs. Hippocampus 14, 919-930.

Kranz, F., and Ishai, A. (2006). Face perception is modulated by sexual preference. Curr. Biol. 16, 63-68.

Krendl, A. C., Macrae, C. N., Kelley, W. M., Fugelsang, J. A., and Heatherton, T. F. (2006). The good, the bad, and the ugly: an fMRI investigation of the functional anatomic correlates of stigma. Soc. Neurosci. 1, 5-15.

Kuhnen, C. M., and Knutson, B. (2005). The neural basis of financial risk taking. Neuron 47, 763-770.

LaBar, K. S., and Cabeza, R. (2006) Cognitive neuroscience of emotional memory. Nat. Rev. Neurosci. 7, 54-64.

Langlois, J. H., Kalakanis, L. Rubenstein, A. J., Larson, A.,
Hallam, M., and Smoot, M. (2000). Maxims or myths of beauty? A meta-analytic and theoretical review. Psychol. Bull. 126, 390-423.

Langlois, J. H., Roggman, L. A., Casey, R. J., and Ritter, J. M. (1987). Infant preferences for attractive faces: rudiments of a stereotype? Dev. Psychol. 23, 363-369.

Laroi, F., D'Argembeau, A., and van der Linden, M. (2006). The effects of angry and happy expressions on recognition memory for unfamiliar faces in delusion-prone individuals. J. Behav. Ther. Exp. Psychiatry 37, 271-282.

Liang, X., Zebrowitz, L. A., and Aharon, I. (2009). Effective connectivity between amygdala and orbitofrontal cortex differentiates the perception of facial expressions. Soc. Neurosci. 4, 185-196.

Liang, X., Zebrowitz, L. A., and Zhang, Y. (2010). Neural activation in the "reward circuit" shows a nonlinear response to facial attractiveness. Soc Neurosci. 5, 320-334.

Light, L. L., Hollander, S., and KayraStuart, F. (1981). Why attractive people are harder to remember? Pers. Soc. Psychol. Bull. 7, 269-276.

Martin-Soelch, C., Leenders, K. L. Chevalley, A. F., Missimer, J., Kunig, G., Magyar, S., Mino, A., and Schultz, W. (2001). Reward mechanisms in the brain and their role in dependence: evidence from neurophysiological and neuroimaging studies. Brain Res. Brain Res. Rev. 36 139-149.

Marzi, T., and Viggiano, M. P. (2010). When memory meets beauty: insights from eventrelated potentials. Biol. Psychol. 84 192-205.

McClure, S. M., York, M. K., and Montague, P. R. (2004). The neural substrates of reward processing in humans: the modern role of fMRI. Neuroscientist 10, 260-268.

Mealey, L., Daood, C., and Krage, M. (1996). Enhanced memory for faces of cheaters. Ethol. Sociobiol. 17, 119-128.

Minagawa-Kawai, Y., Matsuoka, S. Dan, I., Naoi, N., Nakamura, K., and Kojima, S. (2009). Prefrontal activation associated with social attachment: facial-emotion recognition in mothers and infants. Cereb. Cortex 19, 284-292.

Mishkin, M., Suzuki, W. A., Gadian, D. G., and Vargha-Khadem, F. (1997). Hierarchical organization of cognitive memory. Philos. Trans. R. Soc. Lond. B Biol. Sci. 352, 1461-1467.

Morris, J. S., Frith, C. D., Perrett, D. I., Rowland, D., Young, A. W. Calder, A. J., and Dolan, R. J. (1996)
A differential neural response in the human amygdala to fearful and happy facial expressions. Nature $383,812-815$.

Muhlberger, A., Wieser, M. J., Gerdes, A. B., Frey, M. C., Weyers, P., and Pauli, P. (2011). Stop looking angry and smile, please: start and stop of the very same facial expression differentially activate threat- and reward-related brain networks. Soc Cogn. Affect. Neurosci. 6, 321-329.

Nadel, L., and Moscovitch, M. (1997). Memory consolidation, retrograde amnesia and the hippocampal complex. Curr. Opin. Neurobiol. 7, 217-227.

Norman, K. A., and O'Reilly, R. C. (2003). Modeling hippocampal and neocortical contributions to recognition memory: a complementary-learning-systems approach. Psychol. Rev. 110, 611-646.

O’Doherty, J. (2004). Reward representations and reward-related learning in the human brain: insights from neuroimaging. Curr. Opin. Neurobiol. 14, 769-776.

O'Doherty, J., Winston, J., Critchley, H., Perrett, D., Burt, D. M., and Dolan, R. J. (2003). Beauty in a smile: the role of medial orbitofrontal cortex in facial attractiveness. Neuropsychologia 41, 147-155.

Oosterhof, N. N., and Todorov, A. (2008). The functional basis of face evaluation. Proc. Natl. Acad. Sci. U.S.A. 105, 11087-11092.

Paller, K. A., Ranganath, C., Gonsalves, B., Labar, K. S., Parrish, T. B., Gitelman, D. R., Mesulam, M. M., and Reber, P. J. (2003). Neural correlates of person recognition. Learn. Mem. 10, 253-260.

Phillips, M. L., Young, A. W., Scott, S. K., Calder, A. J., Andrew, C. Giampietro, V., Williams, S. C., Bullmore, E. T., Brammer, M., and Gray, J. A. (1998). Neural responses to facial and vocal expressions of fear and disgust. Proc. Biol. Sci. 265 1809-1817.

Phillips, M. L., Young, A. W., Senior, C., Brammer, M., Andrew, C., Calder, A. J., Bullmore, E. T., Perrett, D. I., Rowland, D., Williams, S. C., Gray, J. A., and David, A. S. (1997). A specific neural substrate for perceiving facial expressions of disgust. Nature 389, 495-498.

Platek, S. M., Krill, A. L., and Wilson, B. (2009). Implicit trustworthiness ratings of self-resembling faces activate brain centers involved in reward. Neuropsychologia 47 289-293. 
Powers, K. E., and Heatherton, T. F. (2012). Characterizing socially avoidant and affiliative responses to social exclusion. Front. Integr. Neurosci. 6:46. doi: 10.3389/fnint.2012.00046

Prince, S. E., Dennis, N. A., and Cabeza, R. (2009). Encoding and retrieving faces and places: distinguishing process- and stimulusspecific differences in brain activity. Neuropsychologia 47, 2282-2289.

Righi, S., Marzi, T., Toscani, M., Baldassi, S., Ottonello, S., and Viggiano, M. P. (2012). Fearful expressions enhance recognition memory: electrophysiological evidence. Acta Psychol. (Amst.) 139, $7-18$.

Rilling, J. K., Goldsmith, D. R., Glenn, A. L., Jairam, M. R., Elfenbein, H. A., Dagenais, J. E., Murdock, C. D., and Pagnoni, G. (2008). The neural correlates of the affective response to unreciprocated cooperation. Neuropsychologia 46, 1256-1266.

Rolls, E. T. (2000). The orbitofrontal cortex and reward. Cereb. Cortex 10, 284-294.

Rolls, E. T., Sienkiewicz, Z. J., and Yaxley, S. (1989). Hunger modulates the responses to gustatory stimuli of single neurons in the caudolateral orbitofrontal cortex of the macaque monkey. Eur. J. Neurosci. 1, 53-60.

Said, C. P., Baron, S. G., and Todorov, A. (2009). Nonlinear amygdala response to face trustworthiness: contributions of high and low spatial frequency information. $J$. Cogn. Neurosci. 21, 519-528.

Samanez-Larkin, G. R., Hollon, N. G., Carstensen, L. L., and Knutson, B. (2008). Individual differences in insular sensitivity during loss anticipation predict avoidance learning. Psychol. Sci. 19, 320-323.

Sambataro, F., Dimalta, S., Di Giorgio, A., Taurisano, P., Blasi, G., Scarabino, T., Giannatempo, G., Nardini, M., and Bertolino, A. (2006). Preferential responses in amygdala and insula during presentation of facial contempt and disgust. Eur. J. Neurosci. 24, 2355-2362.

Sanfey, A. G., Rilling, J. K., Aronson, J. A., Nystrom, L. E., and Cohen, J. D. (2003). The neural basis of economic decision-making in the Ultimatum Game. Science 300, 1755-1758.

Seymour, B., O’Doherty, J. P., Dayan, P., Koltzenburg, M., Jones, A. K., Dolan, R. J., Friston, K. J., and Frackowiak, R. S. (2004). Temporal difference models describe higherorder learning in humans. Nature $429,664-667$.

Seymour, B., Singer, T., and Dolan, R. (2007). The neurobiology of punishment. Nat. Rev. Neurosci. 8, 300-311.

Shastri, L. (2002). Episodic memory and cortico-hippocampal interactions. Trends Cogn. Sci. 6, 162-168.

Shimamura, A. P., Ross, J. G., and Bennett, H. D. (2006). Memory for facial expressions: the power of a smile. Psychon. Bull. Rev. 13, 217-222.

Skinner, E. I., Grady, C. L., and Fernandes, M. A. (2010). Reactivation of context-specific brain regions during retrieval. Neuropsychologia 48, 156-164.

Small, S. A., Nava, A. S., Perera, G. M., Delapaz, R., Mayeux, R., and Stern, Y. (2001). Circuit mechanisms underlying memory encoding and retrieval in the long axis of the hippocampal formation. Nat. Neurosci. 4, 442-449.

Sperling, R., Bates, J. F., Cocchiarella, A. J., Schacter, D. L., Rosen, B. R., and Albert, M. S. (2001). Encoding novel face-name associations: a functional MRI study. Hum. Brain Mapp. 14, 129-139.

Sperling, R., Chua, E., Cocchiarella, A., Rand-Giovannetti, E., Poldrack, R., Schacter, D. L., and Albert, M. (2003). Putting names to faces: successful encoding of associative memories activates the anterior hippocampal formation. Neuroimage 20, 1400-1410.

Sprengelmeyer, R., Rausch, M., Eysel, U. T., and Przuntek, H. (1998). Neural structures associated with recognition of facial expressions of basic emotions. Proc. Biol. Sci. 265, 1927-1931.

Stanley, D. A., Sokol-Hessner, P., Banaji, M. R., and Phelps, E. A. (2011). Implicit race attitudes predict trustworthiness judgments and economic trust decisions. Proc. Natl. Acad. Sci. U.S.A. 108, 7710-7715.

Stanley, D. A., Sokol-Hessner, P., Fareri, D. S., Perino, M. T., Delgado, M. R., Banaji, M. R., and Phelps, E. A. (2012). Race and reputation: perceived racial group trustworthiness influences the neural correlates of trust decisions. Philos. Trans. R. Soc. Lond. B Biol. Sci. 367, 744-753.

Suzuki, A., and Suga, S. (2010). Enhanced memory for the wolf in sheep's clothing: facial trustworthiness modulates face-trait associative memory. Cognition 117 224-229.

Tettamanti, M., Rognoni, E., Cafiero, R., Costa, T., Galati, D., and Perani, D. (2012). Distinct pathways of neural coupling for different basic emotions. Neuroimage 59, 1804-1817.

Todorov, A. (2008). Evaluating faces on trustworthiness: an extension of systems for recognition of emotions signaling approach/avoidance behaviors. Ann. N.Y. Acad. Sci. 1124 208-224.

Todorov, A., Baron, S. G., and Oosterhof, N. N. (2008a). Evaluating face trustworthiness: a model based approach. Soc. Cogn. Affect. Neurosci. 3, 119-127.

Todorov, A., Said, C. P., Engell, A. D., and Oosterhof, N. N. (2008b). Understanding evaluation of faces on social dimensions. Trends Cogn. Sci. 12, 455-460.

Todorov, A., and Engell, A. D. (2008), The role of the amygdala in implicit evaluation of emotionally neutral faces. Soc. Cogn. Affect. Neurosci. 3 , 303-312.

Tsukiura, T., and Cabeza, R. (2008), Orbitofrontal and hippocampal contributions to memory for facename associations: the rewarding power of a smile. Neuropsychologia 46, 2310-2319.

Tsukiura, T., and Cabeza, R. (2011a). Remembering beauty: roles of orbitofrontal and hippocampal regions in successful memory encoding of attractive faces. Neuroimage 54, 653-660.

Tsukiura, T., and Cabeza, R. (2011b). Shared brain activity for aesthetic and moral judgments: implications for the Beauty-is-Good stereotype. Soc. Cogn. Affect. Neurosci. 6, 138-148.

Tsukiura, T., Sekiguchi, A., Yomogida Y., Nakagawa, S., Shigemune, Y., Kambara, T., Akitsuki, Y., Taki, Y., and Kawashima, R. (2011). Effects of aging on hippocampal and anterior temporal activations during successful retrieval of memory for face-name associations. J. Cogn. Neurosci. 23, 200-213.

Tsukiura, T., Shigemune, Y., Nouchi, R., Kambara, T., and Kawashima, R. (2012). Insular and hippocampal contributions to remembering people with an impression of bad personality. Soc. Cogn. Affect. Neurosci. [Epub ahead of print].

Tsukiura, T., Suzuki, C., Shigemune, Y., and Mochizuki-Kawai, H. (2008).
Differential contributions of the anterior temporal and medial temporal lobe to the retrieval of memory for person identity information. Hum. Brain Mapp. 29, 1343-1354.

Vuilleumier, P., and Pourtois, G. (2007). Distributed and interactive brain mechanisms during emotion face perception: evidence from functional neuroimaging. Neuropsychologia 45, 174-194.

Willis, J., and Todorov, A. (2006). First impressions: making up your mind after a 100-ms exposure to a face. Psychol. Sci. 17, 592-598.

Winston, J. S., O'Doherty, J., and Dolan, R. J. (2003). Common and distinct neural responses during direct and incidental processing of multiple facial emotions. Neuroimage 20, 84-97.

Winston, J. S., O’Doherty, J., Kilner, J. M., Perrett, D. I., and Dolan, R. J. (2007). Brain systems for assessing facial attractiveness. Neuropsychologia 45, 195-206.

Winston, J. S., Strange, B. A. O'Doherty, J., and Dolan, R. J. (2002). Automatic and intentional brain responses during evaluation of trustworthiness of faces. Nat Neurosci. 5, 277-283.

Zeineh, M. M., Engel, S. A., Thompson, P. M., and Bookheimer, S. Y. (2003). Dynamics of the hippocampus during encoding and retrieval of face-name pairs. Science 299, 577-580.

Conflict of Interest Statement: The author declares that the research was conducted in the absence of any commercial or financial relationships that could be construed as a potential conflict of interest.

Received: 22 March 2012; accepted: 03 July 2012; published online: 24 July 2012. Citation: Tsukiura T (2012) Neural mechanisms underlying the effects of face-based affective signals on memory for faces: a tentative model. Front. Integr. Neurosci. 6:50. doi: 10.3389/fnint. 2012.00050

Copyright (๑) 2012 Tsukiura. This is an open-access article distributed under the terms of the Creative Commons Attribution License, which permits use, distribution and reproduction in other forums, provided the original authors and source are credited and subject to any copyright notices concerning any thirdparty graphics etc. 